\title{
Circumcision - Systematic Review and Meta-Analysis
}

\author{
Jan Kowalski and Jerzy Nowak \\ Department of Urology Medical University of Sopot, Polna, Poland \\ Kowalskiurolog@gmail.com
}

\begin{abstract}
Male circumcision (from Latin circumcidere, meaning "to cut around") ${ }^{[1]}$ is the surgical removal of the foreskin (prepuce) from the human penis. ${ }^{[2][3][4]}$ In the most common procedure, the foreskin is opened and then separated from the glans after inspection. The circumcision device (if used) is placed, and then the foreskin is removed. Topical or locally injected anesthesia is occasionally used to reduce pain and physiologic stress. ${ }^{[5]}$ For adults and children, general anesthesia is an option, and the procedure may be performed without a specialized circumcision device. The procedure is most often an elective surgery performed on neonates and children for religious and cultural reasons. ${ }^{[1]}$ In other cases it may be indicated for both treatment and preventative reasons. Medically, it is a treatment option for pathological phimosis, refractory balanoposthitis and chronic urinary tract infections (UTIs) ${ }^{[2][6]}$ it is contraindicated in cases of certain genital structure abnormalities or poor general health. ${ }^{[3][6]}$
\end{abstract}

The positions of the world's major medical organizations range from considering elective neonatal and child circumcision as having no benefit and significant risks to having a modest health benefit that outweighs small risks. No major medical organization recommends either universal circumcision for all males (aside from the recommendations of the World Health Organization (WHO) for parts of Africa), or banning the procedure. ${ }^{[7]}$ Ethical and legal questions regarding informed consent, and human rights have all been raised over non-therapeutic child and infant circumcision. ${ }^{[8][9]}$

Evidence supports that male circumcision reduces the risk of HIV infection among heterosexual men in sub-Saharan Africa. ${ }^{[10][11]}$ The WHO recommends considering circumcision as part of a comprehensive HIV program in areas with high rates of HIV. ${ }^{[12]}$ Formen who have sex with men the evidence for a health benefit against HIV is less clear. ${ }^{[13][14]}$ Its use to prevent HIV in the developed world is unclear as well. ${ }^{[15]}$ Circumcision in general is associated with reduced rates of cancer causing forms of $\mathrm{HPV}^{[16][17]}$ and risk of both UTIs and penile cancer. ${ }^{[5]}$ Routine circumcision, however, is not justified for the prevention of those conditions. ${ }^{[2][18]}$ Studies of its potential protective effects against other sexually transmitted infections have been unclear. A 2010 review of literature worldwide found circumcisions performed by medical providers to have a median complication rate of $1.5 \%$ for newborns and $6 \%$ for older children, with few cases of severe complications. ${ }^{[19]}$ Bleeding, infection and the removal of either too much or too little foreskin are the most common complications cited. ${ }^{[19]}$ Complication rates are higher when the procedure is performed by an inexperienced operator, in unsterile conditions, or when the child is at an older age ${ }^{[19]}$ Circumcision does not appear to have a negative impact on sexual function. ${ }^{[20][21]}$

An estimated one-third of males worldwide are circumcised. ${ }^{[1][19][22]}$ The procedure is most prevalent in the Muslim world and Israel (where it is near-universal as a religious obligation), the United States and parts of Southeast Asia and Africa; it is relatively rare in Europe, Latin America, parts of Southern Africa and most of Asia. ${ }^{[1]}$ The origin of circumcision is not known with certainty; the oldest documentary evidence for it comes from ancient Egypt. ${ }^{[1]}$ Various theories have been proposed as to its origin, including as a religious sacrifice and as a rite of passage marking oy's entrance into adulthood. ${ }^{[23]}$ It is part of religious law in Judaism ${ }^{[24]}$ and is an established practice in Islam, Coptic Christianity and the Ethiopian Orthodox Church. ${ }^{[1][25][26]}$ The present article is based on the English Wikipedia article. ${ }^{[13]}$

\section{ROUTINE OR ELECTIVE}

Neonatal circumcision is often elected for non-medical reasons, such as for religious beliefs or for personal preferences possibly driven by societal norms. ${ }^{[6]}$ Outside the parts of Africa with high prevalence of HIV/AIDS, the positions of the world's major medical organizations on non-therapeutic 
neonatal circumcision range from considering it as having a modest net health benefit that outweighs small risks to viewing it as having no benefit with significant risks for harm. No major medical organization recommends for universal neonatal circumcision, and no major medical organization calls for banning it either. The Royal Dutch Medical Association, which expresses the strongest opposition to routine neonatal circumcision, does not call for the practice to be made illegal out of their concern that parents who insist on the procedure would turn to poorly trained practitioners instead of medical professionals. This argument to keep the procedure within the purview of medical professionals is found across all major medical organizations. In addition, the organizations advise medical professionals to yield to some degree to parents' preferences, commonly based in cultural or religious views, in the decision to agree to circumcise. ${ }^{[7]}$

The World Health Organization (WHO) and UNAIDS (2007) recommend circumcision as part of a comprehensive program for prevention of HIV transmission in areas with high endemic rates of HIV, as long as the program includes "informed consent, confidentiality, and absence of coercion". ${ }^{[12]}$

\section{MEDiCAL INDiCATIONS}

Circumcision may be used to treat pathological phimosis, refractory balanoposthitis and chronic, recurrent urinary tract infections (UTIs). ${ }^{[2][6]}$ The World Health Organization promotes circumcision as a preventive measure for sexually active men in populations at high risk for HIV. ${ }^{[12]}$ Circumcision is also recommended for HIV prevention by the International Antiviral Society-USA for all sexually active heterosexual males and is recommended that it be discussed with MSM who engage in primarily insertive anal sex with other men, especially in areas where HIV is common. ${ }^{[27]}$

\section{Contraindications}

Circumcision is contraindicated in infants with certain genital structure abnormalities, such as a misplaced urethral opening (as in hypospadias and epispadias), curvature of the head of the penis (chordee), or ambiguous genitalia, because the foreskin may be needed for reconstructive surgery. Circumcision is contraindicated in premature infants and those who are not clinically stable and in good health. ${ }^{[3][6][28]}$ If an individual, child or adult, is known to have or has a family history of serious bleeding disorders (hemophilia), it is recommended that the blood be checked for normal coagulation properties before the procedure is attempted. ${ }^{[6][28]}$

\section{TeChNiQue}

The foreskin extends out from the base of the glans and covers the glans when the penis is flaccid. Proposed theories for the purpose of the foreskin are that it serves to protect the penis as the fetus develops in the mother's womb, that it helps to preserve moisture in the glans, and that it improves sexual pleasure. The foreskin may also be a pathway of infection for certain diseases. Circumcision removes the foreskin at its attachment to the base of the glans. ${ }^{[1]}$

\section{REMOVAL OF THE FORESKIN}

For infant circumcision, devices such as the Gomco clamp, Plastibell and Mogen clamp are commonly used in the USA ${ }^{[5]}$ These follow the same basic procedure. First, the amount of foreskin to be removed is estimated. The practitioner opens the foreskin via the preputial orifice to reveal the glans underneath and ensures it is normal before bluntly separating the inner lining of the foreskin (preputial epithelium) from its attachment to the glans. The practitioner then places the circumcision device (this sometimes requires a dorsal slit), which remains until blood flow has stopped. Finally, the foreskin is amputated. ${ }^{[5]}$ For adults, circumcision is often performed without clamps, ${ }^{[29]}$ and nonsurgical alternatives such as the elastic ring controlled radial compression device or the Shang ring are available. ${ }^{[30]}$

\section{EFFECTS}

A 2014 review found that the benefits of circumcising an infant outweigh the risks of doing so by at least 100 to 1, and that "over their lifetime, half of uncircumcised males will require treatment for a medical condition associated with retention of the foreskin. ${ }^{[36]}$

\subsection{Adverse Effects}

Neonatal circumcision is generally safe when done by an experienced practitioner. ${ }^{[62]}$ The most common acute complications are bleeding, infection and the removal of either too much or too little 
foreskin. ${ }^{[5][63]}$ These complications occur in approximately $0.12 \%$ of procedures, and constitute the vast majority of all acute circumcision complications in the United States. ${ }^{[63]}$ Minor complications are reported to occur in three percent of procedures. ${ }^{[62]}$ A specific complication rate is difficult to determine due to scant data on complications and inconsistencies in their classification. ${ }^{[5]}$ Complication rates are greater when the procedure is performed by an inexperienced operator, in unsterile conditions, or when the child is at an older age. ${ }^{[19]}$ Significant acute complications happen rarely, ${ }^{[5][19]}$ occurring in about 1 in 500 newborn procedures in the United States. ${ }^{[5]}$ Severe to catastrophic complications are sufficiently rare that they are reported only as individual case reports. ${ }^{[5]}$ Other possible complications include buried penis, chordee, phimosis, skin bridges, urethral fistulas, and meatal stenosis. ${ }^{[64]}$ These complications may be avoided with proper technique, and are most often treatable without requiring a hospital visit. ${ }^{[64]}$ The circumcision procedure may carry the risks of heightened pain response for newborns and dissatisfaction with the result. ${ }^{[31]}$ Newborns that experience pain due to being circumcised have different responses to vaccines given afterwards, with higher pain scores observed. ${ }^{[65]}$

\subsection{Sexual Effects}

Circumcision does not appear to decrease the sensitivity of the penis, harm sexual function or reduce sexual satisfaction. ${ }^{[20][66]}$ A 2013 systematic review found that circumcision did not appear to adversely affect sexual desire, pain with intercourse, premature ejaculation, time until ejaculation, erectile dysfunction or difficulties with orgasm. ${ }^{[67]}$ However, the study found that the existing evidence is not very good. ${ }^{[67]}$ Another 2013 systematic review found that the highest-quality studies reported no adverse effects of circumcision on sexual function, sensitivity, sensation or satisfaction. ${ }^{[21]}$ However, A 2014 literature review found that there are significant gaps in the current literature on male and female sexual health that need to be addressed for the literature to be applicable to North American populations. ${ }^{[68]}$

\section{Prevalence}

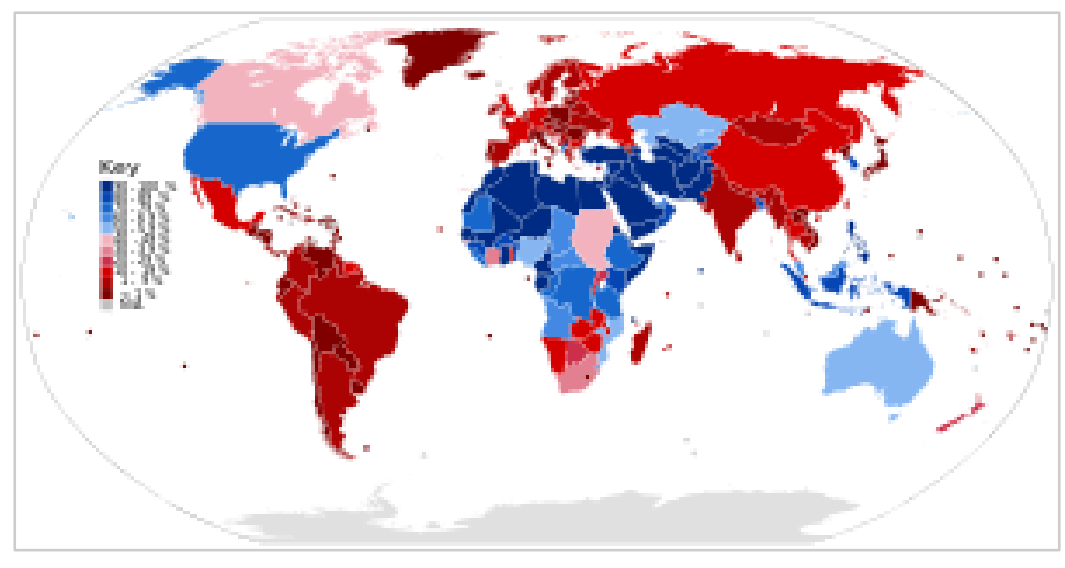

Fig1. Prevalence of circumcision by country

Circumcision is one of the world's most widely performed procedures. ${ }^{[69]}$ Approximately one-third of males worldwide are circumcised, most often for religious or cultural reasons. ${ }^{[1][19][22]}$ It is most often practiced between infancy and the early twenties. ${ }^{[1]}$ The WHO estimated in 2007 that $664,500,000$ males aged 15 and over were circumcised (30-33\% global prevalence), almost 70\% of whom were Muslim. ${ }^{[1]}$ Circumcision is most prevalent in the Muslim world, Israel, South Korea, the United States and parts of Southeast Asia and Africa. It is relatively rare in Europe, Latin America, parts of Southern Africa and Oceania and most of Asia. Prevalence is near-universal in the Middle East and Central Asia. ${ }^{[1][70]}$ Non-religious circumcision in Asia, outside of the Republic of Korea and the Philippines, is fairly rare, ${ }^{[1]}$ and prevalence is generally low (less than 20\%) across Europe. ${ }^{[1][71]}$ Estimates for individual countries include Taiwan at $9 \%{ }^{[72]}$ and Australia 58.7\% ${ }^{[73]}$ Prevalence in the United States and Canada is estimated at $75 \%$ and $30 \%$ respectively. ${ }^{[1]}$ Prevalence in Africa varies from less than $20 \%$ in some southern African countries to near universal in North and West Africa. ${ }^{[70]}$

The rates of routine neonatal circumcision over time have varied significantly by country. In the United States, hospital discharge surveys estimated rates at $64.7 \%$ in the year $1980,59.0 \%$ in the year $1990,62.4 \%$ in the year 2000, and $58.3 \%$ in the year $2010 .{ }^{[74]}$ These estimates are lower than the overall circumcision rates, as they do not account for non-hospital circumcisions, ${ }^{[7]}$ or for procedures 
performed for medical or cosmetic reasons later in life; ${ }^{[1][74]}$ community surveys have reported higher neonatal circumcision. ${ }^{[1]}$ Canada has seen a slow decline since the early 1970 s, possibly influenced by statements from the AAP and the Canadian Pediatric Society issued in the 1970s saying that the procedure was not medically indicated. ${ }^{[1]}$ In Australia, the rate declined in the 1970s and 80s, but has been increasing slowly as of $2004 .^{[1]}$ In the United Kingdom, rates are likely to have been $20-30 \%$ in the 1940s, but declined after the National Health Service (NHS) formed in the late 40s, as it did not pay for the procedure. Another reason may have been a 1949 British Medical Journal article which stated that there was no medical reason for the general circumcision of babies. ${ }^{[1]}$ The overall prevalence of circumcision in South Korea has increased markedly in the second half of the 20th century, rising from near zero around 1950 to about $60 \%$ in 2000, with the most significant jumps in the last two decades of that time period. ${ }^{[1]}$ This is probably due to the influence of the United States, which established a trusteeship for the country following World War II. ${ }^{[1]}$

\section{History}

Circumcision is the world's oldest planned surgical procedure, suggested by anatomist and hyperdiffusionist historian Grafton Elliot Smith to be over 15,000 years old, pre-dating recorded history. There is no firm consensus as to how it came to be practiced worldwide. One theory is that it began in one geographic area and spread from there; another is that several different cultural groups began its practice independently. In his 1891 work History of Circumcision, physician Peter Charles Remondino suggested that it began as a less severe form of emasculating a captured enemy: penectomy or castration would likely have been fatal, while some form of circumcision would permanently mark the defeated yet leave him alive to serve as a slave. ${ }^{[23][75]}$

The history of the migration and evolution of the practice of circumcision is followed mainly through the cultures and peoples in two separate regions. In the lands south and east of the Mediterranean, starting with Sudan and Ethiopia, the procedure was practiced by the ancient Egyptians and the Semites, and then by the Jews and Muslims, with whom the practice travelled to and was adopted by the Bantu Africans. In Oceania, circumcision is practiced by the Australian Aborigines and Polynesians. ${ }^{[75]}$

Circumcision did not become a common medical procedure in the Anglophone world until the late 19th century. ${ }^{[82]}$ At that time, British and American doctors began recommending it primarily as a deterrent to masturbation. ${ }^{[82][83]}$ Prior to the 20th century, masturbation was believed to be the cause of a wide range of physical and mental illnesses including epilepsy, paralysis, impotence, gonorrhea, tuberculosis, feeblemindedness, and insanity. ${ }^{[84][85]}$ In 1855, motivated in part by an interest in promoting circumcision to reduce masturbation, English physician Jonathan Hutchinson published his findings that Jews had a lower prevalence of certain venereal diseases. ${ }^{[86]}$ While pursuing a successful career as a general practitioner, Hutchinson went on to advocate circumcision for health reasons for the next fifty years, ${ }^{[86]}$ and eventually earned a knighthood for his overall contributions to medicine. ${ }^{[87]}$ In America, one of the first modern physicians to advocate the procedure was Lewis Sayre, a founder of the American Medical Association. In 1870, Sayre began using circumcision as a purported cure for several cases of young boys presenting with paralysis or significant motor problems. He thought the procedure ameliorated such problems based on a "reflex neurosis" theory of disease, which held that excessive stimulation of the genitals was a disturbance to the equilibrium of the nervous system and a cause of systemic problems. ${ }^{[82]}$ The use of circumcision to promote good health also fit in with the germ theory of disease, which saw validation during the same time period: the foreskin was seen as harboring infection-causing smegma (a mixture of shed skin cells and oils). Sayre published works on the subject and promoted it energetically in speeches. Contemporary physicians picked up on Sayre's new treatment, which they believed could prevent or cure a wide-ranging array of medical problems and social ills. Its popularity spread with publications such as Peter Charles Remondino's History of Circumcision. By the turn of the century, in both America and Great Britain, infant circumcision was near universally recommended. ${ }^{[23][83]}$

After the end of World War II, Britain moved to a nationalized health care system, and so looked to ensure that each medical procedure covered by the new system was cost-effective. Douglas Gairdner's 1949 article "The Fate of the Foreskin" argued persuasively that the evidence available at that time showed that the risks outweighed the known benefits. ${ }^{[88]}$ The procedure was not covered by the national health care system, and circumcision rates dropped in Britain and in the rest of Europe. In the 1970s, national medical associations in Australia and Canada issued recommendations against routine 
infant circumcision, leading to drops in the rates of both of those countries. The United States made similar statements in the 1970s, but stopped short of recommending against it- simply stating that it has no medical benefit. Since then they has amended their policy statements several times with the current recommendation being that the benefits outweigh the risks, but they do not recommend it routinely. ${ }^{[23][83]}$

An association between circumcision and reduced heterosexual HIV infection rates was suggested in 1986. ${ }^{[23]}$ Experimental evidence was needed to establish a causal relationship, so three randomized controlled trials were commissioned as a means to reduce the effect of any confounding factors. ${ }^{[89]}$ Trials took place in South Africa, Kenya and Uganda. ${ }^{[1]}$ All three trials were stopped early by their monitoring boards on ethical grounds, because those in the circumcised group had a lower rate of HIV contraction than the control group. ${ }^{[11]}$ Subsequently, the World Health Organization promoted circumcision in high-risk populations as part of an overall program to reduce the spread of $\mathrm{HIV},{ }^{[12]}$ although some have challenged the validity of the African randomized controlled trials, prompting a number of researchers to question the effectiveness of circumcision as an HIV prevention strategy. ${ }^{[00][91][92][93]}$ The Male Circumcision Clearinghouse website was formed in 2009 by WHO, UNAIDS, FHI and AVAC to provide current evidence-based guidance, information and resources to support the delivery of safe male circumcision services in countries that choose to scale up the procedure as one component of comprehensive HIV prevention services. ${ }^{\text {[94][95] }}$

\section{REFERENCES}

[1] Lissauer T, Clayden G (October 2011). Illustrated Textbook of Paediatrics, Fourth edition. Elsevier. pp. 352-353. ISBN 978-0-7234-3565-5.

[2] Rudolph C, Rudolph A, Lister G, First L, Gershon A (18 March 2011). Rudolph's Pediatrics, 22nd Edition. McGraw-Hill Companies, Incorporated. p. 188. ISBN 978-0-07-149723-7.

[3] Sawyer S (November 2011). Pediatric Physical Examination \& Health Assessment. Jones \& Bartlett Publishers. pp. 555-556. ISBN 978-1-4496-7600-1.

[4] American Academy of Pediatrics Task Force on Circumcision (2012). "Technical Report". Pediatrics 130 (3): e756-e785.doi:10.1542/peds.2012-1990. ISSN 0031-4005. PMID 22926175.

[5] Hay W, Levin M (25 June 2012). Current Diagnosis and Treatment Pediatrics 21/E. McGraw Hill Professional. pp. 18-19. ISBN 978-0-07-177971-5.

[6] Jacobs, Micah; Grady, Richard; Bolnick, David A. (2012). "Current Circumcision Trends and Guidelines". In Bolnick, David A.; Koyle, Martin; Yosha, Assaf. Surgical Guide to Circumcision. London: Springer. pp. 3-8. doi:10.1007/978-1-4471-2858-8_1.ISBN 978-1-44712857-1. Retrieved April 6, 2014. (Subscription required (help)).

[7] Pinto K (August 2012). "Circumcision controversies". Pediatric clinics of North America 59 (4): 977-986. doi:10.1016/j.pcl.2012.05.015. PMID 22857844.

[8] Caga-anan EC, Thomas AJ, Diekema DS, Mercurio MR, Adam MR (8 September 2011). Clinical Ethics in Pediatrics: A Case-Based Textbook. Cambridge University Press. p. 43. ISBN 978-0-521-17361-2.

[9] Krieger JN (May 2011). "Male circumcision and HIV infection risk". World Journal of Urology 30 (1): 3-13. doi:10.1007/s00345-011-0696-x. PMID 21590467.

[10] Siegfried N, Muller M, Deeks JJ, Volmink J; Muller; Deeks; Volmink (2009). Siegfried, Nandi, ed. "Male circumcision for prevention of heterosexual acquisition of HIV in men". Cochrane Database of Systematic Reviews (2): CD003362.doi:10.1002/14651858.CD003362.pub2. PMID 19370585.

[11] "WHO and UNAIDS announce recommendations from expert consultation on male circumcision for HIV prevention". World Health Organization. March 2007.

[12] Millett GA, Flores SA, Marks G, Reed JB, Herbst JH (October 2008). "Circumcision status and risk of HIV and sexually transmitted infections among men who have sex with men: a metaanalysis". JAMA 300 (14): 1674-84. doi:10.1001/jama.300.14.1674.PMID 18840841.

[13] https://en.wikipedia.org/wiki/Circumcision

[14] Wiysonge CS, Kongnyuy EJ, Shey M; et al. (2011). Wiysonge, Charles Shey, ed. "Male circumcision for prevention of homosexual acquisition of HIV in men". Cochrane Database of Systematic Reviews (6): CD007496.doi:10.1002/14651858.CD007496.pub2. PMID 21678366. 
[15] Kim H, Li PS, Goldstein M, Howard H; Li, Philip S; Goldstein, Marc (November 2010). "Male circumcision: Africa and beyond?". Current Opinion in Urology 20 (6): 5159.doi:10.1097/MOU.0b013e32833f1b21. PMID 20844437.

[16] Larke N, Thomas SL, Dos Santos Silva I, Weiss HA (November 2011). "Male circumcision and human papillomavirus infection in men: a systematic review and meta-analysis". J. Infect. Dis. 204 (9): 1375-90. doi:10.1093/infdis/jir523. PMID 21965090.

[17] Rehmeyer C, CJ (2011). "Male Circumcision and Human Papillomavirus Studies Reviewed by Infection Stage and Virus Type". J Am Osteopath Assoc 111 (3 suppl 2): S11-S18. PMID 21415373.

[18] "Can penile cancer be prevented?". Learn About Cancer: Penile Cancer: Detailed Guide. American Cancer Society. Retrieved 2012-10-25.

[19] Weiss HA, Larke N, Halperin D, Schenker I; Larke; Halperin; Schenker (2010). "Complications of circumcision in male neonates, infants and children: a systematic review". BMC Urol 10: 2. doi:10.1186/1471-2490-10-2. PMC 2835667.PMID 20158883.

[20] The American Academy of Pediatrics Task Force on Circumcision "Technical Report" (2012) addresses sexual function, sensitivity and satisfaction without qualification by age of circumcision. Sadeghi-Nejad et al. "Sexually transmitted diseases and sexual function" (2010) addresses adult circumcision and sexual function. Doyle et al. "The Impact of Male Circumcision on HIV Transmission" (2010) addresses adult circumcision and sexual function. Perera et al. "Safety and efficacy of nontherapeutic male circumcision: a systematic review" (2010) addresses adult circumcision and sexual function and satisfaction.

[21] Morris, BJ; Krieger, JN (November 2013). "Does male circumcision affect sexual function, sensitivity, or satisfaction?--a systematic review.". The Journal of Sexual Medicine10 (11): 2644-57. doi:10.1111/jsm.12293. PMID 23937309.

[22] "Neonatal and child male circumcision: a global review" (PDF). World Health Organization. 2010. Retrieved 2015-04-12.

[23] Alanis MC, Lucidi RS (May 2004). "Neonatal circumcision: a review of the world's oldest and most controversial operation". Obstet Gynecol Surv 59 (5): 379-95.doi:10.1097/00006254200405000-00026. PMID 15097799.

[24] Glass JM (January 1999). "Religious circumcision: a Jewish view". BJUI. 83 Suppl 1: 17-21. doi:10.1046/j.1464-410x.1999.0830s1017.x. PMID 10349410.

[25] "Circumcision". Columbia Encyclopedia. Columbia University Press. 2011.

[26] Clark M (10 March 2011). Islam For Dummies. John Wiley \& Sons. p. 170.ISBN 978-1-11805396-6.

[27] Marrazzo, JM; del Rio, C; Holtgrave, DR; Cohen, MS; Kalichman, SC; Mayer, KH; Montaner, JS; Wheeler, DP; Grant, RM; Grinsztejn, B; Kumarasamy, N; Shoptaw, S; Walensky, RP; Dabis, F; Sugarman, J; Benson, CA; International Antiviral Society-USA, Panel (Jul 23-30, 2014). "HIV prevention in clinical care settings: 2014 recommendations of the International Antiviral Society-USA Panel". JAMA: the Journal of the American Medical Association 312 (4): 390409. doi:10.1001/jama.2014.7999. PMID 25038358.

[28] "Manual for male circumcision under local anaesthesia". World Health Organization. December 2009.

[29] McClung, Chris; Voelzke, Bryan (2012). "Adult Circumcision". In Bolnick, David A.; Koyle, Martin; Yosha, Assaf. Surgical Guide to Circumcision. London: Springer. pp. 165-175. Doi: 10.1007/978-1-4471-2858-8_14. ISBN 978-1-4471-2857-1. Retrieved April 6, 2014. (subscription required (help)).

[30] "Use of devices for adult male circumcision in public health HIV prevention programmes: Conclusions of the Technical Advisory Group on Innovations in Male Circumcision"(PDF). World Health Organization. 2012.

[31] Perera CL, Bridgewater FH, Thavaneswaran P, Maddern GJ; Bridgewater; Thavaneswaran; Maddern (2010). "Safety and efficacy of nontherapeutic male circumcision: a systematic review". Annals of Family Medicine 8 (1): 64-72.doi:10.1370/afm.1073. PMC 2807391. PMID 20065281. 
[32] "Professional Standards and Guidelines - Circumcision (Infant Male)". College of Physicians and Surgeons of British Columbia. September 2009.

[33] Lonnqvist P (Sep 2010). "Regional anaesthesia and analgesia in the neonate". Best Pract Res Clin Anaesthesiol 24 (3): 309-21. doi:10.1016/j.bpa.2010.02.012.PMID 21033009.

[34] Shockley RA, Rickett K; Rickett (April 2011). "Clinical inquiries. What's the best way to control circumcision pain in newborns?". J Fam Pract 60 (4): 233a-b. PMID 21472156.

[35] Wolter C, Dmochowski R (2008). "Circumcision". Handbook of Office Urological Procedures. Springer. pp. 88-. ISBN 978-1-84628-523-3.

[36] Morris, BJ; Bailis, SA; Wiswell, TE (May 2014). "Circumcision rates in the United States: rising or falling? What effect might the new affirmative pediatric policy statement have?".Mayo Clinic Proceedings 89 (5): 677-86. doi:10.1016/j.mayocp.2014.01.001.PMID 24702735.

[37] Uthman OA, Popoola TA, Uthman MM, Aremu O; Popoola; Uthman; Aremu (2010). Van Baal, Pieter H. M, ed. "Economic evaluations of adult male circumcision for prevention of heterosexual acquisition of HIV in men in sub-Saharan Africa: a systematic review".PLoS ONE 5 (3): e9628. doi:10.1371/journal.pone.0009628. PMC 2835757.PMID 20224784.

[38] Weiss HA, Dickson KE, Agot K, Hankins CA; Dickson; Agot; Hankins (2010). "Male circumcision for HIV prevention: current research and programmatic issues". AIDS. 24 Suppl 4: S61-9. doi:10.1097/01.aids.0000390708.66136.f4. PMID 21042054.

[39] "New Data on Male Circumcision and HIV Prevention: Policy and Programme Implications" (PDF). World Health Organization. March 28, 2007.

[40] Dinh MH; Fahrbach KM; Hope TJ (March 2011). "The role of the foreskin in male circumcision: an evidence-based review". Am J Reprod Immunol 65 (3): 279-83.doi:10.1111/j.16000897.2010.00934.x. PMC 3091617. PMID 21114567.

[41] Weiss, HA; Hankins, CA; Dickson, K (November 2009). "Male circumcision and risk of HIV infection in women: a systematic review and meta-analysis". The Lancet. Infectious diseases 9 (11): 669-77. doi:10.1016/S1473-3099(09)70235-X. PMID 19850225.

[42] "Male Circumcision and Risk for HIV Transmission and Other Health Conditions: Implications for the United States". Centers for Disease Control and Prevention. 7 February 2008. Retrieved 15 July 2011.

[43] Templeton DJ, Millett GA, Grulich AE; Millett; Grulich (February 2010). "Male circumcision to reduce the risk of HIV and sexually transmitted infections among men who have sex with men". Current Opinion in Infectious Diseases 23 (1): 45-52.doi:10.1097/QCO.0b013e328334e54d. PMID 19935420.

[44] "STD facts - Human papillomavirus (HPV)". CDC. Retrieved September 12, 2012.

[45] See: Larke et al. "Male circumcision and human papillomavirus infection in men: a systematic review and meta-analysis" (2011), Albero et al. "Male Circumcision and Genital Human Papillomavirus: A Systematic Review and Meta-Analysis" (2012), Rehmeyer "Male Circumcision and Human Papillomavirus Studies Reviewed by Infection Stage and Virus Type" (2011).

[46] Albero G, Castellsagué X, Giuliano AR, Bosch FX (February 2012). "Male Circumcision and Genital Human Papillomavirus: A Systematic Review and Meta-Analysis".Sex Transm Dis 39 (2): 104-113. doi:10.1097/OLQ.0b013e3182387abd.PMID 22249298.

[47] Weiss, HA; Thomas, SL; Munabi, SK; Hayes, RJ (April 2006). "Male circumcision and risk of syphilis, chancroid, and genital herpes: a systematic review and meta-analysis".Sexually Transmitted Infections 82 (2): 101-9; discussion 110.doi:10.1136/sti.2005.017442. PMC 2653870. PMID 16581731.

[48] Wetmore CM, Manhart LE, Wasserheit JN; Manhart; Wasserheit (April 2010)."Randomized controlled trials of interventions to prevent sexually transmitted infections: learning from the past to plan for the future". Epidemiol Rev 32 (1): 121-36.doi:10.1093/epirev/mxq010. PMC 2912604. PMID 20519264.

[49] Hayashi, Y; Kojima, Y; Mizuno, K; Kohri, K (3 February 2011). "Prepuce: phimosis, paraphimosis, and circumcision.". TheScientificWorldJournal 11: 289-301.doi: 10.1100/ tsw.2011.31. PMID 21298220. 
[50] Becker K (January 2011). "Lichen sclerosus in boys". Dtsch Arztebl Int 108 (4): 538.doi:10.3238/arztebl.2011.053. PMC 3036008. PMID 21307992.

[51] Moreno, G; Corbalán, J; Peñaloza, B; Pantoja, T (2 September 2014). "Topical corticosteroids for treating phimosis in boys.". The Cochrane database of systematic reviews 9: CD008973. doi:10.1002/14651858.CD008973.pub2. PMID 25180668.

[52] Celis, S; Reed, F; Murphy, F; Adams, S; Gillick, J; Abdelhafeez, AH; Lopez, PJ (February 2014). "Balanitis xerotica obliterans in children and adolescents: a literature review and clinical series.". Journal of pediatric urology 10 (1): 34-9.doi:10.1016/j.jpurol.2013.09.027. PMID 24295833.

[53] Krill, Aaron; Palmer, Lane; Palmer, Jeffrey (2011). "Complications of Circumcision". ScientificWorldJournal 11: 2458-68. doi:10.1100/2011/373829. PMC 3253617.PMID 22235177.

[54] Leber M, Tirumani A (June 8, 2006). "Balanitis". EMedicine. Retrieved2008-10-14.

[55] Osipov V, Acker S (November 2006). "Balanoposthitis". Reactive and Inflammatory Dermatoses. EMedicine. Retrieved 2006-11-20.

[56] Aridogan IA, Izol V, Ilkit M (August 2011). "Superficial fungal infections of the male genitalia: a review". Crit. Rev. Microbiol. 37 (3): 237-44.doi:10.3109/1040841X.2011.572862. PMID 21668404.

[57] Hayashi Y, Kojima Y, Mizuno K, Kohri K (2011). "Prepuce: phimosis, paraphimosis, and circumcision". ScientificWorldJournal 11: 289-301. doi:10.1100/tsw.2011.31. 